\title{
Sosyal Çalışmacı Adaylarının Koşulsuz Kendini Kabul Etme ve Merhamet Düzeyleri Arasındaki İlişkinin İncelenmesi
}

\author{
Zeki KARATAȘ ${ }^{1}$ ve Metin ÖKSÜZ ${ }^{2}$
}

\section{$\ddot{O} z$}

Koşulsuz kendini kabul; bireyin kendi varlığından bağımsız olarak sadece davranışlarını, düşüncelerini ve duygularını akılcı sınırlar içinde iyi ya da kötü olarak değerlendirerek kendine olumlu değer vermesidir. Sosyal çalışmacı adayı öğrencilerin koşulsuz kendini kabul özelliklerinin gelişmiş olması, yardıma ihtiyacı olan bireylere yönelik etkin sosyal hizmet sunumu açısından önemlidir. Bu araştırmanın amac1; sosyal çalışmacı adayı öğrencilerin koşulsuz kendini kabul düzeylerinin açıklanmasında merhametin ve çeşitli demografik değişkenlerin rolünün incelenmesidir. Araştırma nicel araştırma yöntemine dayalı olarak ilişkisel tarama modeli kullanılarak gerçekleştirilmiştir. Araştırmanın örneklemini iki devlet üniversitesinin sosyal hizmet lisans programında öğrenim gören ve tesadüfi olarak belirlenen 370 öğrenci oluşturmaktadır. Araştırmada veri toplama aracı olarak Koşulsuz Kendini Kabul Ölçeği, Merhamet Ölçeği ve Kişisel Bilgi Formu kullanılmıştır. Elde edilen veriler ANOVA testi, t-testi ve çoklu regresyon analizi kullanılarak incelenmiştir. Araştırmanın sonucunda; katılımcıların koşulsuz kendini kabul düzeyleri ile merhamet düzeyleri arasında düşük düzeyde, olumlu yönde ve anlamlı bir ilişkinin olduğu belirlenmiştir. Öğrenim görülen sınıf düzeyi ve ailesinin ekonomik durumu farklı olan gruplar arasında koşulsuz kendini kabul düzeyi açısından anlamlı farklılık yokken, katılımcıların cinsiyeti, algılanan anne-baba tutumları ve dini inançları uygulama sıklığı ile koşulsuz kendini kabul düzeyi arasında anlamlı farklılık bulunmuştur.

Anabtar Kelimeler: Koşulsuz kendini kabul, Merhamet, Sosyal çalışmacı adayı, Sosyal hizmet, Üniversite öğrencisi

Examining the Relationship between Compassion Levels and Unconditional SelfAcceptance of Social Worker Candidates

\begin{abstract}
Unconditional self-acceptance is the individual's self-appreciation only by evaluating his/her behaviors, thoughts and emotions as good or bad within rational limits, regardless of his own existence. The fact that social worker candidates have improved unconditional self-acceptance characteristics is important in terms of providing effective social services for individuals who need help. The aim of this study is to examine the role of compassion and various demographic variables in the explanation of unconditional self-acceptance levels of social worker candidates. The research was carried out by using relational screening model based on quantitative research method. The sample of the research consists of randomly selected 370 students studying in the social work undergraduate program of two state universities. Unconditional Self-Acceptance Scale, Compassion Scale and Personal Information Form were used as data collection tools in the study. The data obtained were analyzed using ANOVA, t-test and multiple regression analysis. As a result of the research, it was determined that there is a low, positive, and significant relationship between the unconditional self-acceptance level and the compassion level of the participants. While there is no significant difference in terms of unconditional self-acceptance level among the groups studying at different class level, and economic status of the family, a significant difference was found between the unconditional selfacceptance level and gender, the perceived parental attitude and the frequency of applying religious beliefs.
\end{abstract}

Key Words: Unconditional self-acceptance, Compassion, Social worker candidate, Social work, University student

\section{Atıf İçin / Please Cite As:}

Karataş, Z. ve Öksüz, M. (2020). Sosyal çalışmacı adaylarının koşulsuz kendini kabul etme ve merhamet düzeyleri arasındaki ilişkinin incelenmesi. Manas Sosyal Araștırmalar Dergisi, 9(4), 2547-2559.

Geliş Tarihi / Received Date: 16.04.2020

Kabul Tarihi / Accepted Date: 27.08.2020

\footnotetext{
1 Dr. Öğr. Üyesi - Recep Tayyip Erdoğan Üniversitesi İktisadi ve İdari Bilimler Fakültesi, zeki.karatas@erdogan.edu.tr ORCID: 0000-0002-5822-2904

2 Öğr. Gör. - Yalova Üniversitesi İktisadi ve İdari Bilimler Fakültesi, metin.oksuz@yalova.edu.tr

ORCID: 0000-0003-4127-3200
} 


\section{Giriş}

Carl Rogers'in (2007) geliştirdiği birey merkezli yaklaşımdan yararlanan sosyal çalışmacılar müracaatçıyla görüşme yaparken uygun terapötik ortamı oluşturmak için koşulsuz olumlu kabul, empati, içtenlik ve samimiyeti kullanarak kolaylaştırıcı bir rol üstlenmektedirler. Müracaatçıya yönelik koşulsuz olumlu kabul ve saygı sosyal çalışmacının içten ve gerçek ilgi göstermesi, müracaatçının duygu, düşünce ve davranışlarını iyi ve kötü olarak nitelendirmeden, yargilamadan hareket etmesi anlamına gelmektedir (Rogers, 2007, s. 243). Kabullenme müracaatçıların tüm davranışlarının onaylanması değil, kendilerine ait değerlere ve duygulara sahip olma haklarının bulunduğunun bilinmesidir (Corey, 2017, s. 169). Sosyal hizmete ihtiyacı olan bireylere profesyonel yardım sunan sosyal çalş̧macılar, müracaatçıyla ilk karşılaştı̆̆ andan itibaren terapötik iletişim becerilerini kullanmaktadırlar. Çözüme yönelik terapötik ilişki kurmak isteyen sosyal çalışmacının görüşme teknikleri yanında koşulsuz olumlu kabul becerisini de kullanması gerekmektedir (Kadushin ve Kadushin, 2016, s. 90). Hem kendini hem de başkalarını koşulsuz kabul edebilmek öz bilinç, farkındalık, psikolojik sağlamlık, nesnellik, yetkinlik, güvenirlik gibi pek çok özelliğin gelişmiş olmasını gerektirmektedir. Bu nedenle sosyal çalışmacı adayı olan öğrenciler üniversite yıllarında teorik derslerin yanında uygulama da yaparak profesyonel becerilerini ve özelliklerini geliştirmeye çalışmaktadırlar. Sosyal hizmet programında öğrenim gören öğrencilerin, yardıma muhtaç birey ve topluluklarla çalışmaya başlamadan önce güçlü ve zayıf yönleriyle kendini tanıma ve kabullenme çabasında olmaları önemlidir. Kendisiyle ilgili farkındalığı düşük ve koşulsuz kendini kabul özelliği yetersiz olan sosyal çalışmacı adayı öğrencinin mesleki yaşamında şiddet, istismar ve travmaya maruz kalmış vakalarla karşılaşması durumunda duygusal açıdan zorlanması muhtemeldir. Bu açıdan sosyal çalışmacı adayı öğrencilerin bir taraftan sosyal hizmetlerden yararlananların iyi olma hallerine ve işlevselliklerine katkı sunabilme, diğer taraftan da kendi duygularını etkin bir şekilde yönetebilme becerilerini geliştirmeleri gerekmektedir (Kapoulitsas ve Corcoran, 2014, s. 87; Badger vd., 2008, s. 65). Bu nedenle koşulsuz kendini kabul özelliği sosyal çalışmacı adayı öğrenciler açısından son derece önemlidir. Koşulsuz kendini kabul gibi merhamet de yardım sunan meslek elamanlarında olması gereken temel özelliklerdendir. Kendisinin ve başkalarının sıkıntılı durumlarına karşı derin bir farkındalı̆̆ı, sorunlara çözüm bulma isteği ve çabasını içeren merhamet, yardıma muhtaç kişiyi yargılamadan, sabırla kabullenmeyi sağlamaktadır (Nas ve Sak, 2020, s. 66). Dolayısıyla bu çalışmada öncelikle koşulsuz kendini kabul ve merhamet kavramlarıyla ilgili genel bir çerçeve çizilmiş, daha sonra sosyal çalışmacı adayı öğrencilerin bu özellikleri ne düzeyde benimsedikleriyle ilgili araştırma bulguları tartışılmışıtır.

Hümanist psikolojinin önemli kavramlarından birisi olan kendini kabul; kendini keşfetme, öz bilinç ve kendini gerçekleştirme sürecinde oluşan psikolojik bir durumdur. Kendini gerçekleştirmeyi hedefleyen bireyin öncelikle kendini tanıması, güçlü ve zayıf yönleriyle kendini kabul etmesi gerekir (Hoffman vd., 2013, s. 14). Carl Rogers kendini gerçekleştirme eğilimi olan insanların olgunlaşma, özerk olma ve daima gelişebilme kapasitelerinin olduğuna dikkat çekmiştir (Schultz ve Schultz, 2005, s. 341). Öz sayg1 ve öz güven kavramlarılyla yakın anlamda olan koşulsuz kendini kabul, öz saygıdan farklı olarak insanın diğerleri tarafından onaylanma beklentisine girmeden kendini tam ve koşulsuz olarak anlayışla karşılamasıdır (Dryden vd., 2010, s. 242). Albert Ellis'e (1999, s. 50) göre koşulsuz kendini kabul; bireyin kendi varlığından bağımsız olarak sadece davranışlarını, düşüncelerini ve duygularını akılcı sınırlar içinde iyi ya da kötü olarak değerlendirerek kendine olumlu değer vermesi anlamına gelmektedir. Koşulsuz kendini kabul eden kişi kendine değer biçme eylemiyle mücadele etmeli, sadece yaşadığ1 ve insan olduğu için kendine iyi birisi olduğunu söylemeyi seçmelidir. Kişi koşulsuz kendini kabulü kendi değerini olumlu ya da olumsuz bir şekilde derecelendirmeden, hata yapabilirliğini ve kusurluluğunu itiraf ederek gerçekleştirebilir. Kişinin bu anlayışı başkaları ve yaşam için de geliştirmesinin ruh sağlığına katkı sağlayacağı belirtilmektedir (Digiusepte vd., 2014, s. 51). Ellis başkalarının koşulsuz kabul bakış açısını şöyle özetlemektedir: "Davranıslarından nefret et ama kişinin kendisinden değil” (Murdock, 2016, s. 158). Araştırmalar kendini kabul ile başkalarını kabul arasında olumlu ilişki bulunduğunu vurgulamaktadır (Berger, 1952, s. 780). Benlik saygisı yerine koşulsuz kendini kabulü tavsiye eden Ellis (2005, s. 19) koşulsuz kendini kabulün temel özelliklerini şu şekilde sıralamıştr: 1) İyi performans gösterip göstermemesine bağlı olmaksızın kişinin kendi bütünlügünü kararllılkla kabul etmesi veya sayg1 göstermesi, 2) Beğenmediği ya da seçtĭgi hedeflerine uygun olmayan davranışları olduğunda bile kişinin kendisini onaylaması ve saygı duyması, 3) Kişinin benliğini ya da bütünlüğünü değil düşüncelerini, duygularını ve davranışlarını değerlendirmesi ve derecelendirmesidir.

Birey diğer kişilerden aldığı geri bildirimler, değerlendirmeler ve imalarla kendi kişisel deneyim ve yorumlarını birleştirerek kendilik algısını oluşturmaktadır. İnsanın kendisiyle ilgili değerlendirmelerinde sosyal çevreden aldığ tepkiler önemli yer tutmaktadır. Ancak yaşam bireylerin kendi seçimlerinden ve 
tercihlerinden oluştuğu için sorumlulukların farkında olunması gerekir. Bu nedenle koşulsuz kendini kabul sahibi birey başkaları üzerinde nasıl bir izlenim bıraktığına bakmaksızın, kendisiyle ilgili olumsuz değerlendirmelerden etkilenmeden özgün kalabilmeyi başarabilen kişidir (Gedik, 2018, s. 617). Koşulsuz kendini kabullenen birey kişiler arası ilişkilerde savunucu bir iletişim tarzı kullanmaz ve gerçek duygularını gizleme ihtiyacı hissetmez. Koşulsuz kendini kabul düzeyi yüksek olan bireylerin sosyal onay ihtiyaçları daha düşük olmakta ve bu bireyler sorunlar karşısında daha proaktif davranmaktadırlar. Koşulsuz kendini kabule sahip bireyler, güçlü yönlerini kullanarak kendilerini geliştirme konusunda yeniliklere ve eleştirilere daha açık olmakta, farkındalıkları sayesinde zayıf yönleriyle daha kolay başa çıkabilmektedirler (Topses, 2013, s. 62). Rosenberg (1965, s. 31) insanların kendilerini kabul etme ve kendilerine değer verme özelliklerini benlik saygısı olarak tanımlamış ve sağlıklı yaşam için gerekli olduğunu vurgulamıştır. Kendi benliğinden rahatsız olan ve sürekli yapıp ettiklerini eleştiren mükemmeliyetçi kişilerin de kendilerini kabul düzeylerinin düşük olduğu belirtilmiştir (Chang, 2006, s. 695).

Koşulsuz kendini kabulle merhamet ilişkisinin araştırıldığı bu çalışmada kısaca merhamet kavramı üzerinde durulmasında yarar görülmektedir. Arapça kökenli olup acıma, şefkat etme, esirgeme anlamlarına gelen merhamet kelimesi Türkçe sözlükte; "bir kimsenin veya bir başka canlının karşılaştı̆̆ kötü durumdan dolayı duyulan üzüntü, acıma" olarak tanımlanmaktadır (TDK, 2011). Psikolojik bir kavram olarak merhamet; "bir insanı tanımak, ihtiyaçlarını anlamak, ilişkisel anlayış ve eylem yoluyla acılarını iyileştirmek için erdemli ve kasıtlı bir tepki" anlamında kullanılmaktadır (Singh vd., 2020, s. 607). Bireyin içsel süreçte başkalarının acısını, sıkıntısını hissetmesi ve gidermek için eyleme geçme arzusu taşıması şeklinde oluşan merhamet, sosyal yaşamın işlevsel bir şekilde sürdürülmesinde önemli bir rol oynamaktadır. Aynı zamanda önemli bir insani erdem olarak merhamet; din ve felsefenin de temel kavramları arasında yer almaktadır. Dini açıdan merhamet; yaratılanlara müsamaha ve iyilikle yaklaşarak ihtiyaç duydukları yardımı ulaştırma niyeti ve eylemi içinde bulunmaktır (Hökelekli, 2008, s. 78). Felsefi açıdan ahlaklı kişide bulunması gereken en temel güdünün merhamet olduğunu vurgulayan Schopenhauer (2007, s. 75), merhameti en büyük kötülük olan acımasızlı̆̆ın ve bencilliğin karşıtı olarak tanımlamıştır. Kişisel, kişilerarası iyi oluşun ve sosyal refahın önemli bir bileşeni olan merhametin; acı çeken kişinin farkında olmak, acıyı hafifletmeye istekli olmak ve acıyı azaltmak için eyleme geçmek gibi üç temel bileşeni bulunmaktadır (Nas ve Sak, 2020, s. 66).

Literatürde siklıkla merhamet (Gilbert, 2009; Gündüzoğlu vd., 2019), öz merhamet (Jay Miller vd., 2019; Dilmaç vd., 2009) ve merhamet yorgunluğu (Sprang vd., 2007; Polat ve Erdem, 2017) konularında araştırmalara rastlanmaktadır. Merhamet duygusunu kişinin kendisi için kullanması öz merhamet olarak nitelendirilmektedir. Öz merhamet acı, başarısızlık ve yetersizliklerin insanlık durumunun bir parçası olduğunu ve herkesin -kendisi de dâhil- şefkate layık olduğunu kabul etmeyi gerektirmektedir (Neff, 2003, s. 225). Profesyonel yardım mesleği uygulayanların yardıma ihtiyacı olanların halini anlayıp destek olmaya çalısırken, duygusal açıdan tükenmişlik yaşaması da merhamet yorgunluğu olarak tanımlanmaktadır (Adams vd., 2006, s. 104). Araştırmalarda; kabul ve tolerans düzeyi yüksek olan bireylerin başkalarını suçlama düzeylerinin düșük, merhamet düzeylerinin yüksek olduğu belirtilmektedir (Williams ve Lynn, 2010, s. 26). Ayrıca merhamet düzeyi yüksek bireylerin daha yüksek yaşam doyumu, sosyal bağlllık, duygusal zekâ ve mutluluk düzeyine sahip oldukları; daha az kaygı, depresyon, utanç, başarısızlık korkusu ve tükenmişlik yaşadıkları vurgulanmaktadır (Barnard ve Curry, 2011, s. 295). Bir meta-analiz çalışmasında; merhamet temelli müdahalelerin iyi olma halini artırma ve sıkıntıyı azaltma konusunda umut vadettiği belirtilmiştir (Kirby vd., 2017, s. 787).

Literatür incelendiğinde koşulsuz kendini kabulle farklı kavramların ilişkisinin incelendiği araștırmalara rastlamak mümkündür. Koşulsuz kendini kabulün benlik saygısı (Thompson ve Waltz, 2008), mükemmeliyetçilik (Chang, 2006), psikolojik iyi oluş (Xu vd., 2016), depresyon (Flett vd., 2003), psikolojik sağlık (Chamberlain ve Haaga, 2001) gibi kavramlarla ilişkisinin incelendiği araştırmalarda koşulsuz kendini kabul düzeyi yüksek bireylerin psikolojik açıdan daha sağlıklı olduğu, kayg1 ve depresyon düzeylerinin de daha düşük olduğu belirtilmektedir. Türkiye'de Yılmaz-Bingöl ve Vural-Batık'in (2018, s. 2447) psikolojik danışman adayı öğrenciler üzerine yaptıkları bir araştırmada; PDR öğrencilerinin koşulsuz kendini kabulleri orta düzeyde olumlu bulunmuştur. Taranan belli başlı indekslerde koşulsuz kendini kabulle ilgili sosyal hizmet öğrencileri üzerine yapılan herhangi bir araştırmaya rastlanmamıstır. Bu nedenle sosyal çalışmacı adayı öğrencilerin koşulsuz kendini kabul özelliklerinin merhamet ve bazı sosyo-demografik değişkenlerle ilişkisinin incelenmesinin, literatüre katkı sağlaması açısından önemli olduğu düşünülmektedir.

Yukarıda değinilen açıklamalar 1şı̆̆ında bu araştırmanın amacı; sosyal çalışmacı adayı olan sosyal hizmet lisans programı öğrencilerinin koşulsuz kendini kabullerinin açıklanmasında merhamet ve çeşitli demografik değişkenlerin rolünün incelenmesidir. Bu amaç doğrultusunda aşağıldaki sorulara cevap 
aranmıştır: 1) Sosyal çalışmacı adayı öğrencilerin koşulsuz kendini kabul etme ve merhametleri ne düzeydedir? 2) Sosyal çalışmacı adayı öğrencilerin koşulsuz kendini kabul etme ile merhamet ve çeşitli sosyo-demografik değişkenler arasında anlamlı bir ilişki var mıdır?

\section{Yöntem}

Nicel araştırma yaklaşımına dayalı olarak tasarlanan bu araştırmada, ilişkisel tarama modeli kullanılmıştır. Bu modelde var olan bir durumu herhangi bir değiştirme girişiminde bulunulmadan, iki veya daha fazla sayıdaki değişken arasındaki ilişkinin yönü ve derecesinin belirlenmesi amaçlanmıştır (Karasar, 2008, s. 79). Bu araştırmada da temel olarak sosyal çalışmacı adayı öğrencilerin koşulsuz kendini kabul tutumlarıyla merhamet düzeyleri ve çeşitli sosyo-demografik değişkenler arasındaki ilişkiler belirlenmeye çalışılmıştır. Çalışmanın bilimsel uygunluğu için Recep Tayyip Erdoğan Üniversitesi'nin Sosyal ve Beşeri Bilimler Etik Kurulu'ndan 13.04.2020 tarih ve 2020/15 sayılı Etik Onay alınmıştır.

\section{Çalı̧̧ma Evreni ve Örneklem}

Bu araştırmanın evrenini 2018-2019 eğitim öğretim y1lında Recep Tayyip Erdoğan Üniversitesi ve Yalova Üniversitesi Sosyal Hizmet Programı'nda öğrenim gören 935 öğrenci (656 öğrenci Yalova, 279 öğrenci RTE Üniversitesi) oluşturmaktadır (YÖK, 2020). Araştırmanın örneklemi tesadüfi örnekleme tekniği ile belirlenmiştir. Örneklem grubu adı geçen bölümlerde öğrenim gören ve araştırmaya gönüllü katılım sağlayan 370 öğrenciden oluşmaktadır. Katılımcılara ilişkin tanımlayıcı bilgiler Tablo 1'de sunulmuştur.

Tablo 1. Katılimalara İlişkin Tammlayıcı Bilgiler ( $n=370)$

\begin{tabular}{|c|c|c|c|}
\hline Değişken & & $\mathbf{n}$ & $\%$ \\
\hline \multirow{2}{*}{ Cinsiyet } & Kadın & 288 & 77,8 \\
\hline & Erkek & 82 & 22,2 \\
\hline \multirow{2}{*}{ Yaş } & $18-24$ & 357 & 96,5 \\
\hline & $25+$ & 13 & 3,5 \\
\hline \multirow{2}{*}{$\begin{array}{l}\text { Öğrenim görülen } \\
\text { üniversite }\end{array}$} & Recep Tayyip Erdoğan Üniversitesi & 114 & 30,8 \\
\hline & Yalova Üniversitesi & 256 & 69,2 \\
\hline \multirow{4}{*}{ Sınıf düzeyi } & 1. Sinif & 68 & 18,4 \\
\hline & 2. Sinif & 141 & 38,1 \\
\hline & 3. Sinif & 103 & 27,8 \\
\hline & 4. Sinif & 58 & 15,7 \\
\hline \multirow{3}{*}{$\begin{array}{l}\text { Genel akademik } \\
\text { not ortalamas1 }\end{array}$} & Düşük & 10 & 2,7 \\
\hline & Orta & 192 & 51,9 \\
\hline & Yüksek & 168 & 45,4 \\
\hline \multirow{2}{*}{$\begin{array}{l}\text { Staj/Uygulama } \\
\text { yapma durumu }\end{array}$} & Evet & 90 & 24,3 \\
\hline & Hayır & 280 & 75,7 \\
\hline \multirow{2}{*}{$\begin{array}{l}\text { STK'da görev alma } \\
\text { durumu }\end{array}$} & Evet & 191 & 51,6 \\
\hline & Hayır & 179 & 48,4 \\
\hline \multirow{3}{*}{$\begin{array}{l}\text { Ailenin algylanan } \\
\text { gelir düzeyi }\end{array}$} & Düşük & 22 & 5,9 \\
\hline & Orta & 337 & 91,1 \\
\hline & Yüksek & 11 & 3,0 \\
\hline \multirow{4}{*}{$\begin{array}{l}\text { Ailenin yerleşim } \\
\text { yeri }\end{array}$} & Belde/Köy & 50 & 13,5 \\
\hline & İlçe merkezi & 120 & 32,4 \\
\hline & İl merkezi & 61 & 16,5 \\
\hline & Büyükşsehir & 139 & 37,6 \\
\hline \multirow{8}{*}{$\begin{array}{l}\text { Anne-baba } \\
\text { tutumlar1 }\end{array}$} & Otoriter & 4 & 1,1 \\
\hline & İlgisiz ve kavitsız & 5 & 1,4 \\
\hline & Serbest & 9 & 2,4 \\
\hline & Dengesiz ve kararsiz & 16 & 4,3 \\
\hline & Koruyucu & 84 & 22,7 \\
\hline & Mükemmeliyetçi & 19 & 5,1 \\
\hline & Demokratik & 205 & 55,4 \\
\hline & İzin verici & 27 & 7,3 \\
\hline \multirow{4}{*}{$\begin{array}{l}\text { Varsa dini inançları } \\
\text { uygulama sıklı̆̆1 }\end{array}$} & Yok & 18 & 4,9 \\
\hline & Nadiren & 61 & 16,5 \\
\hline & Ara sira & 182 & 49,2 \\
\hline & Düzenli & 109 & 29,5 \\
\hline
\end{tabular}

Tablo 1'de katılımcıların sosyo-demografik özellikleri incelendiğinde; \%77,8'inin kadın, \%22,2'sinin erkek, \%96,5'inin 18-24 yaş aralığında olduğu, \%38,1'inin ikinci sınıfta öğrenim gördüğü, \%51,9’unun orta düzeyde akademik başarıya sahip olduğu, \%32,4’ünün ailesinin ilçede ikamet ettiği, \% \% 91,1 'inin ailesinin 
ekonomik durumunun orta düzeyde olduğu, \%55,4'ünün ebeveyninin demokratik tutum sergilediği, $\% 49,2$ 'sinin dini inancını ara sıra uyguladığ1 görülmüştür.

\section{Veri Toplama Araçları}

Kişisel Bilgi Formu: Katılımcılara ait cinsiyet, yaş, öğrenim görülen üniversite, sınıf düzeyi, algılanan gelir düzeyi, ailenin yaşadığ1 yerleşim yeri, staj/uygulama yapma durumu, STK'da görev alma durumu, ebeveyn tutumu, dini inancını uygulama sıklı̆ıına ilişkin bilgilere ulaşılmasına yönelik soruların yer aldığı ve araştırmacılar tarafindan hazırlanan formdur.

Koşulsuz. Kendini Kabul Ölgeğgi: Chamberlain ve Hagaa (2001) tarafindan geliştirilen, Acun-Kapıkıran ve Kapıkıran (2010) tarafından Türkçeye uyarlanan Koşulsuz Kendini Kabul Ölçeği 19 maddeden oluşmaktadır. Ölçek maddelerinde "(1) her zaman geçersiz" ile "(7) her zaman geçerli" arasında değişen Likert tipi 7'li derecelendirme kullanılmaktadır. Albert Ellis'in Rasyonel Duygucu Davranışçı Kuramı çerçevesinde temellendirilmiş olan ölçek, koşullu ve koşulsuz kendini kabulü içeren iki alt ölçekten oluşmaktadır. Ölçeğin koşullu kendini kabul alt boyutunu içeren maddeleri (1, 4, 6, 7, 8, 9, $10,12,13,14,15,19)$ ters puanlanmakta olup, tüm maddelerin toplanmasiyla tek bir puan elde edilmektedir. Ölçeğin her bir maddesi ile madde toplam puanları $\mathrm{r}=.36$ ile $\mathrm{r}=.72$ arasında anlamlı düzeyde ilişki saptanmıştır. Koşulsuz Kendini Kabul Ölçeği’nin 19 maddesinin toplamlarının alfa katsayısı .76 olarak hesaplanmıştır. Koşulsuz Kendini Kabul alt ölçeği .71, Koşullu Kendini Kabul alt ölçeği .77 olarak hesaplanmıştır. Psikolojik nitelikleri ölçen ölçeklerin .70 ve yukarı düzeyde güvenirlik katsayısı olması genel olarak yeterli görülmektedir (Büyüköztürk, 2018). Ölçeğin güvenirliği için gerçekleştirilen Cronbach alfa katsayıs1 .72 olarak kaydedilmiştir. Bu araştırmada da Cronbach alfa değeri .72 olarak hesaplanmıştır.

Merhamet Ölç̧ği: Pommier (2011) tarafindan geliştirilen, Akdeniz ve Deniz (2016) tarafindan Türkçeye uyarlanan Merhamet Ölçeği 24 maddeden oluşmakta ve ölçek maddeleri “(5) her zaman” ve "(1) hiçbir zaman” arasında değişen 5'li Likert tipinde derecelendirilmektedir. Ölçek sevecenlik (6, 8, 16, 24), umursamazlık $(2,12,14,18)$, paylaşımların bilincinde olma $(11,15,17,20)$, bağlantısızlık $(3,5,10,22)$, bilinçli farkındalık $(4,9,13,21)$ ve ilişki kesme $(1,7,19,23)$ olmak üzere altı alt boyuttan oluşmaktadır. Ölçeğin umursamazlık, bağlantısızlık ve ilişki kesme alt boyutları ters çevrilerek hesaplanmakta ve bu hesap sonrasında toplam puan ortalaması alınmaktadır. Ölçekten alınabilecek en yüksek puan 120 , en düşük puan 24 'tür ve toplam puan arttıkça merhamet düzeyi de artmaktadır. Ölçek için yapılan DFA'da, merhamet yapısını oluşturan altı boyutun varlığı doğrulanmıştır. Ölçeğin uyum indeksleri GFI= .90, RMSEA= 061 , $\mathrm{CFI}=.94 ; \mathrm{NFI}=.91$ ve IFI $=.094$ olarak bulunmuştur. İç tutarlık güvenirlik katsayıları ölçeğin tümü için .85 iken alt ölçekler için sırasıyla $.73, .64, .66, .67, .70$ ve .60 olarak bulunmuştur. Bu araştırmada ise Cronbach Alfa değeri .86 olarak hesaplanmıştır.

\section{Verilerin Toplanması ve Analizi}

Çalışmanın amacina uygun olarak araştırmacılar tarafindan oluşturulan Kişisel Bilgi Formu ve ölçekler çevrimiçi ortama aktarılmıştır. Verilerin toplanması için çevrimiç̧i ortamın linki öğrencilerle paylaşılmış ve öğrencilerin onamları alındıktan sonra gönülllülük esasına göre katılımları sağlanmıştır.

Verilerin analizi SPSS 22 programı ile yapılmış olup, bu araştırmanın amacı doğrultusunda öncelikle katılımcıların koşulsuz kendini kabul tutumlarının ne düzeyde olduğu ve çeşitli sosyo-demografik değişkenlerle ilişkisi incelenmiştir. Koşulsuz Kendini Kabul Ölçeği’nin kategorik değişsenlere göre farkllık gösterme durumu, parametrik test tekniklerinden ANOVA ve t testleri ile analiz edilmiştir. Ancak bazı verilerin frekansının düşük olması nedeniyle parametrik olmayan testler kullanılmıştır. Daha sonra katılımcıların merhamet düzeylerinin koşulsuz kendini kabullerini yordayıp yordamadığının belirlenmesi amacıyla çoklu regresyon analizi gerçekleştirilmiştir.

\section{Bulgular}

Bu bölümde araştırmanın amacı doğrultusunda öncelikle üniversite öğrencilerinin koşulsuz kendini kabul ve merhamet tutumlarının ne düzeyde olduğu belirlenmiştir. Daha sonra katılımcıların koşulsuz kendini kabul düzeylerinin merhamet ve çeşitli sosyo-demografik değişkenlerle ilişkisi analiz edilmiştir. Öğrencilerin sosyo-demografik özelliklerine ilişkin betimsel istatistikler Tablo 1'de sunulmuştur. Diğer analizleri içeren istatistikler aşağıdaki tablolarda yer almaktadır. 
Tablo 2. Koşullu/Koşulsuz Kendini Kabul ve Merbamet Düreyine İlişkin Betimsel Istatistikler

\begin{tabular}{lccccccc}
\hline Ölçekler & $\mathbf{n}$ & Minimum & Maximum & Ortalama & ss & Çarpıklık & Basıklık \\
\hline Koşulsuz Kendini Kabul Düzeyi & 370 & 2,21 & 5,74 & 4,072 &, 66 &, 037 &,- 193 \\
Koşullu Kabul Düzeyi & 370 & 2,25 & 6,83 & 4,464 &, 86 &,- 002 &,- 357 \\
Merhamet Düzeyi & 370 & 2,79 & 5,00 & 4,249 &, 44 &,- 705 &, 266 \\
\hline
\end{tabular}

Tablo 2 incelendiğinde; katılımcıların koşulsuz kendini kabul düzeyi puan ortalaması 4,07士0,66;

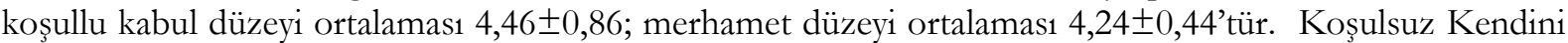
Kabul ve Merhamet Ölçeği puanlarından elde edilen çarpıklık ve basıklık değeri $+1,5$ ile $-1,5$ arasında olduğundan normallik sağlanmış olup (Huck, 2012), analizlerde parametrik olan test teknikleri kullanılmıştır. Ancak bazı değişkenlerin frekansının düşük olduğu durumlarda parametrik olmayan testler kullanılmıştır

Tablo 3. Kosulsuz. Kendini Kabul Düreyinin Cinsiyet, Uygulama Yapma ve Gönüllü Calışma Açsından Incelenmesi

\begin{tabular}{|c|c|c|c|c|c|c|c|}
\hline Koşulsuz Kendini Kabul Düzeyi & Değişken & $\mathbf{n}$ & Ortalama & ss & sd & $\mathbf{t}$ & $\mathrm{p}$ \\
\hline \multirow{2}{*}{ Cinsiyet } & Kadin & 288 & 4,11 & 0,68 & 368 & 2,207 &, $02 *$ \\
\hline & Erkek & 82 & 3,93 & 0,55 & & & \\
\hline \multirow{2}{*}{ Uygulama Yapma Durumu } & Evet & 90 & 4,07 & ,69 & 368 &,- 010 & ,99 \\
\hline & Hayır & 280 & 4,07 & ,65 & & & \\
\hline \multirow{2}{*}{ STK’da Gönüllü Çalışma Durumu } & Evet & 191 & 4,08 & ,63 & 368 & ,402 & ,68 \\
\hline & Hayır & 179 & 4,05 & ,69 & & & \\
\hline
\end{tabular}

$* \mathrm{p}<0,05$

Tablo 3'de koşulsuz kendini kabul düzeyi ile cinsiyet, uygulama yapma ve gönüllü çalışma durumu arasındaki ilişkinin incelenmesi için yapılan t-testi sonuçlarına göre; koşulsuz kendini kabul ile sadece cinsiyet arasında anlamlı bir farklllık bulunmakta, diğer değişkenler açısından herhangi bir farklılık bulunmamaktadır. Kadınların ortalaması 4,11 iken, erkeklerin ortalaması 3,93'tür. Buna göre kadınların koşulsuz kendini kabul düzeyleri daha yüksektir.

Tablo 4. Koşulsuz Kendini Kabul Düzeyinin Smen Düzeyi ve Yerlesim Yeri Açssndan Incelenmesi

\begin{tabular}{llccccc}
\hline Koşulsuz Kendini Kabul Düzeyi & Değişken & $\mathbf{n}$ & Ortalama & ss & $\mathbf{F}$ & $\mathbf{p}$ \\
\hline \multirow{4}{*}{ Sınıf Düzeyi } & 1. Sinıf & 68 & 4,14 &, 75 &, 586 &, 62 \\
& 2. Sinıf & 141 & 4,02 &, 66 & & \\
& 3. Sinıf & 103 & 4,07 &, 62 & \\
\hline \multirow{4}{*}{ Ailenin Yerleşim Yeri } & 4. Sinıf & 58 & 4,11 &, 63 & \\
& Belde/Köy & 50 & 4,03 &, 62 & 1,310 &, 27 \\
& İlçe Merkezi & 120 & 4,03 &, 64 & & \\
& İl Merkezi & 61 & 4,22 &, 70 & & \\
& Büyükşsehir & 139 & 4,05 &, 67 & \\
\hline
\end{tabular}

Tablo 4'de koşulsuz kendini kabul düzeyinin öğrenim görülen sınıf düzeyi ve ailenin yerleşim yeri açısından incelenmesi için yapılan ANOVA testi sonuçlarına göre; bu değişkenlerle koşulsuz kendini kabul düzeyi arasında istatistiksel olarak anlamlı bir farklılık bulunmamaktadır.

Tablo 5. Koşulsuz Kendini Kabul Düreyinin Akademik. Başar ve Ailenin Ekonomik. Durumu Açısından Incelenmesi

\begin{tabular}{|c|c|c|c|c|c|c|c|}
\hline Koşulsuz Kendini Kabul Düzeyi & Değişken & $\mathrm{n}$ & Sira Ortalamas1 & Sd & $\mathrm{X}^{2}$ & $\mathrm{p}$ & İkili Fark \\
\hline \multirow{3}{*}{ Genel Akademik Başarı } & Düşük $(0-1,99)$ & 10 & 146,80 & 2 & 6,838 & $03^{*}$ & $2<3$ \\
\hline & Orta $(2-2,99)$ & 192 & 174,23 & & & & \\
\hline & Yüksek (3-4) & 168 & 200,69 & & & & \\
\hline \multirow{3}{*}{ Ailenin Algilanan Ekonomik Durumu } & Düşük & 22 & 186,66 & 2 & 811 & ,66 & -- \\
\hline & Orta & 337 & 184,50 & & & & \\
\hline & Yüksek & 11 & 213,95 & & & & \\
\hline
\end{tabular}
$* \mathrm{p}<0,05$

Tablo 5'de koşulsuz kendini kabul düzeyinin genel akademik başarı ve ailenin algılanan ekonomik durumu açısından incelenmesi için yapılan Kruskal Wallis H Testi sonuçlarına göre; ailenin algılanan ekonomik durumuyla öğrencilerin koşulsuz kendini kabul düzeyleri arasında anlamlı bir farklılık bulunamamıştır. Öğrencilerin genel akademik başarı ortalamaları ile koşulsuz kendini kabul düzeyleri arasında ise anlamlı farklılık bulunmaktadır. Anlamlı farklılı̆̆ın kaynağını belirleyebilmek için gruplar 
arasında yapılan Mann Whitney U Testi sonuçlarına göre; başarı ortalaması yüksek olan öğrencilerin, başarı ortalaması orta olan öğrencilere göre koşulsuz kendini kabul düzeyleri daha yüksektir.

Tablo 6. Koşulsuz. Kendini Kabul Düzeyinin Anne-Baba Tutumlar ve Dini Inançlar Uygulama Sıkliğg Açısından Incelenmesi

\begin{tabular}{|c|c|c|c|c|c|c|c|}
\hline $\begin{array}{l}\text { Koşulsuz Kendini Kabul } \\
\text { Düzeyi }\end{array}$ & Değişken & $\mathbf{n}$ & Sira Ortalaması & Sd & $\mathbf{X}^{2}$ & $\mathrm{p}$ & İkili Fark \\
\hline \multirow{8}{*}{$\begin{array}{l}\text { Algilanan Anne-Baba } \\
\text { Tutumlar1 }\end{array}$} & Otoriter & 4 & 194,88 & 7 & 22,945 & ,00* & $4<7$ \\
\hline & İlgisiz ve kayıtsız & 5 & 173,20 & & & & $5<7$ \\
\hline & Serbest & 9 & 234,44 & & & & \\
\hline & Dengesiz ve kararsiz & 16 & 124,16 & & & & \\
\hline & Koruyucu & 84 & 159,77 & & & & \\
\hline & Mükemmelivetçi & 19 & 175,92 & & & & \\
\hline & Demokratik & 206 & 204,34 & & & & \\
\hline & İzin verici & 27 & 143,35 & & & & \\
\hline \multirow{4}{*}{$\begin{array}{l}\text { Varsa Dini İnançları Uygulama } \\
\text { Sıklığı }\end{array}$} & Yok & 18 & 199,92 & 3 & 8,294 & ,04* & $2<4$ \\
\hline & Nadiren & 61 & 167,64 & & & & $3<4$ \\
\hline & Ara sira & 182 & 176,41 & & & & \\
\hline & Düzenli & 109 & 208,28 & & & & \\
\hline
\end{tabular}

$* \mathrm{p}<0,05$

Tablo 6'da koşulsuz kendini kabulün algılanan anne-baba tutumları ve dini inançları uygulama sıklı̆ğ açısından incelenmesi için yapılan Kruskal Wallis H Testi sonuçlarına göre; bu iki değişkenle kendini kabul düzeyi arasında istatistiksel olarak anlamlı farklılık bulunmaktadır. Anlamlı farklılı̆ın kaynağını belirleyebilmek için gruplar arasında yapılan Mann Whitney U Testi sonuçlarına göre; ebeveynleri koruyucu, dengesiz ve kararsız tutuma sahip öğrencilerin koşulsuz kendini kabul düzeyleri demokratik tutuma sahip öğrencilerden daha düşüktür. Dini inançlarını nadiren ve ara sıra uyguladığını belirten öğrencilerin koşulsuz kendini kabul düzeyleri dini inançlarını düzenli uyguladığını belirten öğrencilerden daha düşüktür.

Tablo 7. Merbametin Koșulsuz. Kendini Kabulü Yordamasma İliskin Yapulan Çoklu Regresyon Analiæi

\begin{tabular}{|c|c|c|c|c|c|c|c|c|c|}
\hline Bağımsız Değişken & $\mathbf{B}$ & Std. Hata & $\beta$ & t & $\mathrm{p}$ & İkili r & K1smi r & TV & VIF \\
\hline Sabit & 2.988 & .328 & & 9.104 & .000 & & & & \\
\hline Merhamet & .255 & .077 & .171 & 3.321 & .001 & .171 & .171 & .1000 & 1.000 \\
\hline
\end{tabular}

Tablo 7 incelendiğinde; katılımcların koşulsuz kendini kabul düzeyleri ile merhamet düzeyleri arasında düşük düzeyde, olumlu yönde ve anlamlı bir ilişkinin olduğu ve merhametin, koşulsuz kendini kabulün \%03'ünü açıkladığı görülmektedir $\left(\mathrm{R}=.17, \mathrm{~F}_{(1-368)}=11.027, \mathrm{p}<.01\right)$.

\section{Tartı̧̧ma, Sonuç ve Öneriler}

Araştırmaya katılan sosyal çalışmacı adaylarının koşulsuz kendini kabullerinin orta düzeyde $(\% 58,1)$ olumlu, merhametlerinin ise yüksek düzeyde $(\% 89,2)$ olumlu olduğu görülmüştür. Katıllmcıların koşulsuz kendini kabul düzeyleri ile merhamet düzeyleri arasında çok düşük ama pozitif yönlü anlamlı bir ilişki olduğu bulunmuştur. Benzer şekilde Yılmaz-Bingöl ve Vural-Batık'ın (2018, s. 2445) yaptıkları araştırmada; psikolojik danışman adayı öğrencilerin koşulsuz kendini kabullerinin orta düzeyde $(\% 56,9)$ olumlu olduğu belirtilmiştir. Yetişkinler üzerine yapılan başka bir araştırmada katılımcıların koşulsuz kendini kabul düzeyleri düşük bulunmuştur (Chamberlain ve Haaga, 2001, s. 168). Ergenler üzerine yapılan bir araştırmada; katıllımcıların koşulsuz kendini kabul puanlarının orta düzeyde olduğu görülmüştür (CucuCiuhan ve Dumitru, 2017, s. 34). Başer ve Tekin'in (2019, s. 86) araştırmasında; sosyal hizmet programı öğrencilerinin merhamet düzeylerinin yüksek (\%82) olduğu belirtilmiştir. Hemşirelik öğrencileri üzerine yapılan bir araştırmada ise katıllımcıların merhamet düzeylerinin yüksek olduğu vurgulanmıştır (Gündüzoğlu vd., 2019, s. 108). Literatürde koşulsuz kendini kabul etmeyle merhamet arasındaki ilişkiyi inceleyen araştırmaya rastlanmamakla birlikte, koşulsuz kendini kabul düzeyi ile farklı psikolojik kavramların karşılaşıırıldığı araştırmalar bulunmaktadır. Örneğin; farkındalık, benlik saygısı ve koşulsuz kendini kabul etmenin karşılaştırıldığ bir araştırmada, bu değişkenler arasında olumlu ilişki bulunmuştur (Thompson ve Waltz, 2008, s. 123). Depresyon ve anksiyete ile koşulsuz kendini kabul düzeyi arasında anlamlı ilişski bulunmuştur. Koşulsuz kendini kabul düzeyi arttıkça depresyon ve anksiyete düzeyi düşmektedir (Cucu-Ciuhan ve Dumitru, 2017, s. 34; Chamberlain ve Haaga, 2001, s. 171). Benzer şekilde 
koşulsuz kendini kabul düzeyi düşük olan katılımclar, yüksek düzeyde koşulsuz kendini kabulü olanlardan daha endişeli ve depresif bulunmuştur (Popov vd., 2016, s. 77). Koşulsuz kendini kabul düzeyi yüksek olanların bir suçu affetme eğiliminin daha yüksek olduğu görülmüştür (Porada vd., 2018, s. 246). Psikolojik iyi olma ile koşulsuz kendini kabul arasında düşük düzeyde ilişki olduğu belirtilmiştir (Yllmaz-Bingöl ve Vural-Batık, 2019, s. 72). Sosyal çalışmacı adayı öğrencilerin koşulsuz kendini kabul düzeylerinin olumlu fakat düşük olması, kendilerine yönelik değerlendirmelerde başkalarından onay ve takdir beklemeleri, eleştirilmekten rahatsızlık duymaları ve başarılı olmakla değerli olmayı bir tutmaları gibi tutumlarıly açıklanabilir. Örneğin ölçekte yer alan "takdir edilmek bir birey olarak kendimi daha değerli hissetmemi sağlar" cümlesine, öğrencilerin \%91,5’i olumlu düzeyde katıldığını belirtmiştir. Bu durum katıllımcıların kendileriyle ilgili değerlendirmelerde başkalarının onayının önemli bir yer tuttuğunu göstermektedir. Sosyal çalışmacı adayı öğrencilerin merhametle ilgili tutumları incelendiğinde; merhamet düzeylerinin yüksek olması, başkalarının acıları ve sorunlarıyla ilgilenmeyi gerektirecek profesyonel yardım işinde çalışmak üzere eğitim almalarıyla ilişkili olduğu düşünülmektedir. Başkalarının duygularını ve acılarını anlamaya yardımc1 olan becerilerden empatinin sosyal hizmet programında Bireylerle Sosyal Hizmet, Gruplarla Sosyal Hizmet, Sosyal Hizmette Görüşme Teknikleri, Sosyal Hizmet Kuramları gibi derslerde (Erbay ve Sevin, 2013, s. 33) sıklıkla işlendiği göz önüne alındığında öğrencilerin merhamet tutumlarının gelişmiş olması normal kabul edilmektedir.

Araştırmada elde edilen sonuçlara göre; koşulsuz kendini kabul düzeyi ile cinsiyet, akademik başarı, algılanan anne-baba tutumları ve dini inançları uygulama sıklı̆̆ arasında anlamlı bir farklılık olduğu; ögrenim görülen sınıf düzeyi, uygulama yapma ve gönüllü çalışma, ailenin algılanan ekonomik durumu ve yerleşim yeri gibi değişkenler arasında ise herhangi bir farklılık olmadığı bulunmuştur. Benzer şekilde üniversite öğrencileri üzerine yapılan araştırmalarda katılımcıların koşulsuz kendini kabul tutumlarıly cinsiyet arasında anlamlı ilişki bulunmuştur (Kişi, 2019; Yılmaz-Bingöl ve Vural-Batık, 2019; Kuyumcu ve Rohner, 2018). Bazı araştırmalarda da yaş, cinsiyet ve gelirin koşulsuz kendini kabul tutumlarını etkilemediği belirtilmektedir (Scott, 2007; Yllmaz-Bingöl ve Vural-Batık, 2018; Haica, 2013; Jibeen, 2017). $\mathrm{Bu}$ araştırmada kadın öğrencilerin koşulsuz kendini kabul tutumlarının erkeklerden biraz farklı çıkması kadın katılımcıların oranının yüksek olmasıyla açıklanabilir. Ayrıca son yıllarda kadınların eğitime katılmaları için ulusal ölçekte farkındalık ve destek çalışmalarının yapılması, ailelerin kız çocuğuna verdiği değerin artması kadınların koşulsuz kendini kabul etmelerinde etkili olmaktadır (Kağı̆tçıbaşı ve Ataca, 2017, s. 92). Bir başka sonuç; koşulsuz kendini kabul düzeyi yüksek öğrencilerin akademik başarılarının da yüksek olmasıdır. Koşulsuz kendini kabul düzeyi yüksek olan öğrencilerin gelecekle ilgili gerçekçi hedeflere sahip olduğu ve bu doğrultuda öz disiplini sağlayarak düzenli ders çalıstığı düşünülmektedir.

Ebeveyn tutumlarıyla koşulsuz kendini kabul arasında ilişkiyi ele alan doğrudan bir araştırmaya rastlanmamakla birlikte ergenlerin koşulsuz kendini kabul ya da benlik saygısı tutumlarının aile yapısından etkilendiğini belirten araştırmalar bulunmaktadır (Walęcka-Matyja, 2014, s. 69; Adana ve Kutlu, 2009, s. 22). Sezer ve Oğuz'un (2010, s. 753) yaptığı çalışmada; ebeveyn tutumlarının demokratik olmadığı ailelerde kendilik değerinin düşük olduğu belirtilmiştir. Bireyin sağllklı kişilik gelişiminde aile içindeki psikolojik atmosferin önemli bir yeri vardır. Ana-babaların çocuk yetiştirme konusundaki temel değerleri, tutum ve davranışları çocukların kişiliğini şekillendirmekte, ruh sağlığını etkilemektedir. Literatürde çok farklı anababa tarzlarından bahsedilmekle birlikte demokratik/dengeli, yetkeci/otoriter ve izin verici olmak üzere üç temel tarzın kabul edildiği görülmektedir (Sümer vd., 2010, s. 43). Bu araştırmada anne-babasının demokratik tutuma sahip olduğunu belirten katılımcıların koşulsuz kendini kabul düzeyleri anne-babasının dengesiz ve kararsız, ilgisiz ve kayıtsız tutuma sahip olduğunu ifade eden öğrencilerden daha yüksek olduğu görülmüştür. Araştırmalarda anne-babaları demokratik tutuma sahip üniversite öğrencilerinin benlik saygılarının yüksek, ilgisiz ailelerde ise daha düşük olduğu belirtilmiştir (Baybek ve Yavuz, 2005, s. 94). Sezer ve Yıldırım'ın (2018, s. 106) yaptığı araştırmada; düşük düzeyde demokratik anne baba tutumu algılayan gençlerin, orta ve yüksek düzeyde demokratik anne baba tutumu algılayan gençlere göre kendilerini daha olumsuz değerlendirdikleri vurgulanmıştır. Bireyin koşulsuz kendini kabul etmesinde kendisiyle ilgili gerçekçi yargıları ve değerlendirmeleri önemli yer tutmaktadır. Demokratik tutuma sahip ebeveynlere sahip bireyler, koşulsuz sevgi gördükleri, fikirleri önemsendiği, duygularını paylaşabildikleri ve kararlara katılımları desteklendiği için kendilerini kabul düzeyleri daha yüksek olmaktadır.

$\mathrm{Bu}$ araştırmada dini inançları uygulama sıklı̆̆ ile koşulsuz kendini kabul arasında anlamlı ilişki bulunması, inancın bireyin benliğine kattığı olumlu özelliklerden kaynaklandığı düşünülebilir. Benlik sayg1sı, insanların kendilerini kabul etme ve değer verme derecesi olarak tanımlanmaktadır (Rosenberg, 
1965, s. 3). Benlik saygısı ve farkındalık ile koşulsuz kendini kabul arasında pozitif korelasyon olduğu bilinmektedir (Thompson ve Waltz, 2008, s. 124). Dindarlık da benlik saygisını ve farkındalı̆̆ güçlendiren bir unsur olarak karşımıza çıkmaktadır. Kendini kabul etme ile benlik saygısı arasında da yüksek pozitif bir ilişki bulunmaktadır (Chamberlain ve Haaga, 2001, s. 169). Kımter'in (2011, s. 55) üniversite öğrencileri üzerine yaptığı araştırmada; katılımcıların dini hayatın inanç boyutundan aldıkları puanlar yükseldikçe benlik saygısı puanlarında bir artış olduğu; dini hayatın inanç boyutundan aldıkları puanlar düştükçe benlik saygısı puanlarında da bir düşme eğiliminin söz konusu olduğu vurgulanmıştır. Yetişkinler üzerine yapılan bir araştırmada; tahkiki (ilmi) dindarlık ile benlik saygısı arasında pozitif ve anlamlı bir ilişki olduğu belirtilmiştir (Topuz, 2013, s. 148). Benzer şekilde bir başka araştırmada da dini motivasyon ve dini şuur ile özsayg1 arasında pozitif ilişki olduğu tespit edilmiştir (Karslı, 2017, s. 42). Bu bilgiler ışığında dini inancının gereğini yerine getiren öğrencilerin kendilerini kabulde olumlu yönde daha esnek davrandıkları ifade edilebilir.

$\mathrm{Bu}$ araştırmadan elde edilen sonuçlar iki devlet üniversitesinin sosyal hizmet lisans programı öğrencileriyle sınırlıdır. Farklı üniversitelerde ve farklı programlarda öğrenim gören öğrencilerin de dâhil edildiği geniş kapsamlı araştırmalar yapılması önerilebilir. Ayrıca sosyal çalışmacı adaylarının kendileriyle ilgili farkındalıklarının ve benlik saygılarının arttırılmasında önemli bir kavram olan koşulsuz kendini kabul ile empati, stresle başa çıkma, problem çözme gibi farklı kavramların arasındaki ilişkilerin incelendiği yeni araştırmaların yapılmasında yarar görülmektedir. Sosyal çalışmacı adayı öğrenciler mezun olduklarında psikososyal yardım mesleğini uygulayacakları için üniversite öğrenimleri sırasında psikolojik sağlamlıklarını geliştirme adına koşulsuz kendini kabul becerilerini artıracak interaktif çalışmalara katılmaları gerekmektedir. Bu amaçla sosyal hizmet programlarının ders içeriklerinde kendini keşfetme, kişisel özelliklerinin farkına varma ve kabullenme gibi özelliklerin geliştirilmesini sağlayacak etkinliklere yer verilmesinin önemli olduğu düşünülmektedir. Sosyal hizmet programlarında teorik dersler yanında uygulama da önemli bir yer tutmaktadır. Uygulamada öğrencilerin standart çalışmaları yerine getirmesinin yanında, süpervizyon desteği sağlanarak gözlemlediği her bir vakada kendisinin yaşadığı duygusal zorluklar ele alınıp koşulsuz kendini kabul, merhamet gibi özellikleri nasıl geliştirecekleri üzerinde durulmalıdır. Bunun yanında öğrencilerin koşulsuz kendini kabul düzeylerini arttıracak grup psikoeğitimi çalışmalarının yapılmasının yararlı olacağı değerlendirilmektedir.

\section{Etik Beyan}

"Sosyal Callsmacu Adaylarmm Kosulsuz, Kendini Kabul Etme ve Merhamet Düreyleri Arasindaki İlişkinin Incelenmesi" başlıklı çalışmanın yazım sürecinde bilimsel kurallara, etik ve alıntı kurallarına uyulmuş; toplanan veriler üzerinde herhangi bir tahrifat yapılmamış ve bu çalışma herhangi başka bir akademik yayın ortamına değerlendirme için gönderilmemiştir. Bu çalışma kapsamında gerçekleştirilen araştırma, Recep Tayyip Erdoğan Üniversitesi Sosyal ve Beşeri Bilimler Etik Kurulu'nun 13.04.2020 tarih ve 2020/15 sayıll Etik Kurul Değerlendirme Raporu ile etik açıdan uygun bulunmuştur.

\section{Kaynakça}

Acun-Kapıkıran, N. ve Kapıkıran, Ş. (2010). Koşulsuz kendini kabul ölçeğinin Türk üniversite öğrencileri için geçerliği ve güvenirliği. Kriæ Dergisi, 18(1), 33-44.

Adams, R. E., Boscarino, J. A. ve Figley, C. R. (2006). Compassion fatigue and psychological distress among social workers: A validation study. American Journal of Orthopsychiatry, 76(1), 103-108.

Adana, F. ve Kutlu, Y. (2009). Anne-baba tutumlarının adolesanların kendilik kavramı üzerine etkisi. Atatürk Üniversitesi Hemşirelik. Yüksekokulu Dergisi, 12(2), 18-23.

Akdeniz, S. ve Deniz, M. E. (2016). Merhamet ölçeğinin Türkçe'ye uyarlanması: Geçerlik ve güvenirlik çalsşması. The Journal of Happiness \& Well-Being, 4(1), 50-61.

Badger, K., Royse, D. ve Craig, C. (2008 ). Hospital social workers and indirect trauma exposure: An exploratory study of contributing factors. Health \& Social Work, 33(1), 63-71.

Barnard, L. K. ve Curry, J. F. (2011). Self-compassion: Conceptualizations, correlates and interventions. Review of General Psychology, 15(4), 289-303.

Başer, D. ve Tekin, H. H. (2019). Sosyal hizmet öğrencilerinin merhamet ve özgecilik düzeylerinin incelenmesi. İçinde M. Kırlıoğlu ve H. H. Tekin (Edt.), Güncel sosyal hiz̧met çalışmalar (s. 82-89). Konya: Çizgi Kitabevi.

Baybek, H. ve Yavuz, S. (2005). Muğla Üniversitesi öğrencilerinin benlik saygilarının incelenmesi. Muğla Üniversitesi SBE Dergisi, 14, 73-95. 
Berger, E. M. (1952). The relation between expressed acceptance of self and expressed acceptance of others. The Journal of Abnormal and Social Psychology, 47(4), 778-782.

Büyüköztürk, Ş. (2018). Sosyal bilimler için veri analiži el kitabı (24. Baskı). Ankara: Pegem Akademi.

Chamberlain, J. M. ve Haaga, D. A. (2001). Unconditional self-acceptance and psychological health. Journal of Rational-Emotive \& Cognitive-Behavior Therapy, 19(3), 163-176.

Chang, E. C. (2006). Conceptualization and measurement of adaptive and maladaptive aspects of performance perfectionism: Relations to personality, psychological functioning, and academic achievement. Cognitive Therapy and Research, 30, 677-697.

Corey, G. (2017). Theory and practice of counseling and psychotherapy. Cengage Learning: Boston.

Cucu-Ciuhan, G. ve Dumitru, I. E. (2017). Unconditional self-acceptance, functional and dysfunctional negative emotions, and self-esteem as predictors for depression in adolescents: A brief pilot study conducted in Romania. Journal of Experiential Psychotherapy, 20(4), 30-38.

Digiusepte, R. A., Doyle, K. A., Dryden, W., ve Backx, W. (2014). A practitioner's guide to rational emotive behavior therapy. USA: Oxford University Press.

Dilmaç, B., Deniz, M. ve Deniz, M. E. (2009). Üniversite öğrencilerinin öz-anlayış1ları ile değer tercihlerinin incelenmesi. Değerler Eğitimi Dergisi, 7(18), 9-24.

Dryden, W., David, D. ve Ellis, A. (2010). Rational emotive behavior therapy. In K. S. Dobson (Edt.), Handbook of cognitive behavioral therapies (s. 226-276). New York, USA: The Guilford Press.

Ellis, A. (1999). How to make yourself happy. Atascadero, CA: Impact.

Ellis, A. (2005). The myth of self-esteem: How rational emotive behavior therapy can change your life forever. Amherst, NY: Prometheus Books.

Erbay, E. ve Sevin, Ç. (2013). Hacettepe Üniversitesi sosyal hizmet 4. sinıf öğrencilerinin eğitim süreçlerine ve gelecekteki meslek yaşamlarına ilişkin görüşleri. Toplum ve Sosyal Hiæ̧met, 24(1), 25-39.

Flett, G. L., Besser, A., Davis, R. A. ve Hewitt, P. L. (2003). Dimensions of perfectionism, unconditional self-acceptance, and depression. Journal of Rational-Emotive and Cognitive-Behavior Therapy, 21(2), 119138.

Gedik, G. (2018). Bilinçli farkındalık ve kendini kabul. Akademik Sosyal Araştırmalar Dergisi, 6(71), 615-626.

Gilbert, P. (2009). Introducing compassion-focused therapy. Advances in Psychiatric Treatment, 15, $199-208$. doi:10.1192/apt.bp.107.005264

Gündüzoğlu, N. Ç., Akın-Korhan, E., Kuzeyli-Yıldırım, Y., Şenuzun-Aykar, F. ve Üstün, Ç. (2019). Hemşirelik öğrencilerinde merhamet düzeyi. Journal of Human Rbythm, 5(2), 104-116.

Haica, C. C. (2013). Gender differences in quality of life, intensity of dysfunctional attitudes, unconditional self-acceptance, emotional distress and dyadic adjustment of infertile couples. Procedia-Social and Behavioral Sciences, 78, 506-510.

Hoffman, L., Lopez, A. J. ve Moats, M. (2013). Humanistic Psychology and Self-Acceptance . M. E. Bernard içinde, The Strength of Self-Acceptance Theory, Practice and Research (s. 3-18). New York: Springer .

Hökelekli, H. (2008). Merhamet. Dem Dergisi, 1(4), 78-84.

Huck, S. W. (2012). Reading statistics and research (6 $6^{\text {th }}$ Edition). Boston: Pearson.

Jay Miller, J., Lee, J., Shalash, N. ve Poklembova, Z. (2019). Self-compassion among social workers. Journal of Social Work, 1-15. doi:10.1177/1468017319829404

Jibeen, T. (2017). Unconditional self acceptance and self esteem in relation to frustration intolerance beliefs and psychological distress. Journal of Rational-Emotive \&o Cognitive-Behavior Therapy, 35, $207-221$.

Kadushin, A. ve Kadushin, G. (2016). Sosyal hizmet görüsme teknikleri. Ankara: Nika Yayınevi.

Kağıtçıbaşı, C.. ve Ataca, B. (2017). Çocuğun değeri ve aile değişimi: Türkiye'den otuz y1llık bir portre. Sosyoloji Dergisi, 35, 77-101.

Kapoulitsas, M. ve Corcoran, T. (2014). Compassion fatigue and resilience: A qualitative analysis of social work practice. Qualitative Social Work: Research and Practice, 14(1), 86-101.

Karasar, N. (2008). Bilimsel araştırma yöntemi. Ankara: Nobel Yayınc1lı.

Karslı, N. (2017). Gençlerde özsayg1-dindarlık ilişkisi. Avrasya Sosyal ve Ekonomi Araştırmalar Dergisi, 4(6), $16-46$.

Kımter, N. (2011). Üniversiteli gençlerde dindarlık ile benlik sayg1sı arasındaki ilişki üzerine bir araştırma. Cank.rn Karatekin Üniversitesi Sosyal Bilimler Enstitüsü Dergisi, 2(2), 39-60.

Kirby, J. N., Tellegen, C. L. ve Steindl, S. R. (2017). A meta-analysis of compassion-based interventions: Current state of knowledge and future directions. Behavior Therapy, 48(6), 778-792.

Kişi, F. A. (2019). Üniversite ögrencilerinde koşulsuz kendini kabulün algulanan stres ile iliskisisi ve anne kabul/ reddinin bu ilişkideki aracı rolü (Yüksek Lisans Tezi). Işık Üniversitesi Sosyal Bilimler Enstitüsü, İstanbul. 
Kuyumcu, B. ve Rohner, R. P. (2018). The relation between remembered parental acceptance in childhood and self-acceptance among young Turkish adults. International Journal of Psychology, 53(2), 126-132. doi:10.1002/ijop.12277

Murdock, N. L. (2016). Theories of counseling and psychotherapy: A case approach (4th Edition). NY: Pearson.

Nas, E. ve Sak, R. (2020). Merhamet ve merhamet odaklı terapi. Celal Bayar Üniversitesi Sosyal Bilimler Dergisi, 18(1), 64-84.

Neff, K. D. (2003). The development and validation of a scale to measure self-compassion. Self and Identity, 2(3), 223-250.

Polat, F. N. ve Erdem, R. (2017). Merhamet yorgunluğu düzeyinin çalışma yaşam kalitesi ile ilişkisi: sağllk profesyonelleri örneği. Süleyman Demirel Üniversitesi Sosyal Bilimler Enstitüsü Dergisi, 26, 291-312.

Pommier, E. A. (2011). The compassion scale. Dissertation Abstracts International Section A: Humanities and Social Sciences, 72, 1174.

Popov, S., Radanović, J. ve Biro, M. (2016). Unconditional self-acceptance and mental health in egoprovoking experimental context. Suvremena Psibologija, 19(1), 71-80.

Porada, K., Sammut, S. ve Milburn, M. (2018). Empirical investigation of the relationships between irrationality, self-acceptance, and dispositional forgiveness. Journal of Rational-Emotive \& CognitiveBehavior Therapy volume, 36, 234-251.

Rogers, C. R. (2007). The necessary and sufficient conditions of therapeutic personality change. Psychotherapy: Theory, Research, Practice, Training, 44(3), 240-248.

Rosenberg, M. (1965). Society and the adolescent self image. Princeton : Princeton University Press.

Schopenhauer, A. (2007). Merhamet (Çev: Z. Kocatürk) İstanbul: Dergâh Yayınları.

Schultz, D. P. ve Schultz, S. E. (2005). Theories of personality (8th ed.). California: Thomson Wadsworth.

Scott, J. (2007). The effect of perfectionism and unconditional self-acceptance on depression. Journal of Rational-Emotive \& Cognitive-Behavior Therapy, 25, 35-64.

Sezer, Ö. ve Oğuz, V. (2010). Üniversite öğrencilerinde kendilerini değerlendirmelerinin ana baba tutumları ve bazı sosyo demografik değişkenler açısından incelenmesi. Kastamonu Eğitim Dergisi, 18(3), 743-758.

Sezer, Ö. ve Yıldırım, O. (2018). Üniversite öğrencilerinin algılanan anne baba tutumlarına göre kendilerini değerlendirmelerinin ve kardeş ilișkilerinin incelenmesi. Aile Psikolojik Damıșmanluğ Dergisi, 1(1), 86117.

Singh, P., King-Shier, K. ve Sinclair, S. (2020). South Asian patients' perceptions and experiences of compassion in healthcare. Ethnicity \& Health, 25, 1-19.

Sprang, G., Clark, J. J. ve Whitt-Woosley, A. (2007). Compassion fatigue, compassion satisfaction, and burnout: Factors 1mpacting a professional's quality of life. Journal of Loss and Trauma, 12(3), 259-280.

Sümer, N., Gündoğdu-Aktürk, E. ve Helvacı, E. (2010). Anne-baba tutum ve davranışlarının psikolojik etkileri: Türkiye'de yapılan çalısmalara toplu bakış. Türk Psikoloji Yaz̨lar, 13(25), 42-59.

TDK. (2011). Güncel Türkese Sözlük (11. Baskı). Ankara: Türk Dil Kurumu Yayınlar1.

Thompson, B. L. ve Waltz, J. A. (2008). Mindfulness, self-esteem, and unconditional self-acceptance. Journal of Rational-Emotive \& Cognitive-Behavior Therapy, 26(2), 119-126.

Topses, G. (2013). Psikolojik danışma sürecinde kendini kabul ve savunucu davranış kavramlarının felsefi ve psikolojik boyutları. Folklor/edebiyat Dergisi, 19(74), 61-72.

Topuz, I. (2013). Dindarlık tipolojileri ile benlik saygısı arasındaki ilişki: Yetişkinler üzerine bir araştırma. SDÜ Fen Edebiyat Fakültesi Sosyal Bilimler Dergisi, 30, 139-154.

Walęcka-Matyja, K. (2014). Adolescent personalities and their self-acceptance within complete families, incomplete families and reconstructed families. Polish Journal of Applied Psychology, 12(1). doi:10.1515/pjap-2015-0004

Williams, J. C. ve Lynn, S. J. (2010). Acceptance: An historical and conceptual review. Imagination, Cognition and Personality, 30(1), 5-56.

Xu, W., Oei, T. P., Liu, X., Wang, X. ve Ding, C. (2016). The moderating and mediating roles of selfacceptance and tolerance to others in the relationship between mindfulness and subjective well-being. Journal of Health Psychology, 21(7), 1446-1456.

Yılmaz-Bingöl, T. ve Vural-Batık, M. (2018). Psikolojik danışman adaylarının koşulsuz kendini kabul düzeyleri. Insan ve Toplum Bilimleri Arastırmalar Dergisi, 7(4), 2438-2453.

Yılmaz-Bingöl, T. ve Vural-Batık, M. (2019). Unconditional self-acceptance and perfectionistic cognitions as predictors of psychological well-being. Journal of Education and Training Studies, 7(1), 67-75. 
YÖK. (2020). YÖK lisans atlası. Mart 15, 2020 tarihinde Yükseköğretim program atlası: https://yokatlas.yok.gov.tr adresinden alındı

\section{EXTENDED ABSTRACT}

The purpose of this study is to examine the role of compassion and various demographic variables in explaining the unconditional self-acceptance of students who are candidates for social workers. Unconditional self-acceptance means the individual's giving value to himself/herself only by evaluating his/her behavior, thoughts and emotions as good or bad within rational limits, regardless of his own existence. In this respect, unconditional self-acceptance is an important feature for professionals who give psychosocial support services. Compassion, as well as unconditional self-acceptance, is one of the basic characteristics that professional staff should have. Compassion includes somebody's deep awareness of his/her and others' troubles, and the desire and effort to find solutions to problems, and provides to accept the individuals in need without judging them. In the available literature, no research investigating the relationship between unconditional self-acceptance and compassion levels of the social work program students has been found. Students studying in the social work program will provide services by using their characteristics such as unconditional self-acceptance and compassion when working with people who need help in their professional life. Therefore, it is thought that it is important to determine the extent to which the social worker candidates have these features and whether there is any relation between these them.

Studies conducted on unconditional self-acceptance and compassion show that these features have a positive effect on individuals' mental health and psychological well-being. Individuals with high unconditional self-acceptance levels have lower social approval needs and are more proactive in the face of problems. Individuals with unconditional self-acceptance are more open to innovations and criticism in developing themselves by using their strengths and they can cope with their weaknesses more easily thanks to their awareness. In addition, it is emphasized that individuals with a high level of compassion have higher levels of life satisfaction, social connectedness, emotional intelligence and happiness while they experience less anxiety, depression, shame, fear of failure and burnout. In this respect, it can be stated that high unconditional self-acceptance and compassion levels of individuals play an important role in experiencing a functional life and helping others. In this research, in which the role of compassion and various socio-demographic variables was examined in the explanation of the unconditional self-acceptance characteristics of the candidate social worker candidates studying in the social work program, answers were sought for the following questions:

1. What is the level of unconditional self-acceptance and compassion of the prospective social workers?

2. Is there a significant relationship between unconditional self-acceptance of the candidate social workers and compassion and various socio-demographic variables?

Relational screening model was used in this research, which was designed based on the quantitative research approach. The population of the research consists of students studying at Recep Tayyip Erdoğan University and Yalova University Social Work Program in the 2018-2019 academic year. The sample of the research consists of randomly selected 370 students studying in the aforementioned departments. Unconditional Self Acceptance Scale, Compassion Scale and Personal Information Form were used as data collection tools in the study. Ethical approval was obtained from the Recep Tayyip Erdogan University Social and Humanities Ethics Committee to collect data from the participants at the beginning of the study. After obtaining the necessary permissions, the Personal Information Form and the scales were transferred to the online environment by the researchers. In order to collect data, the link of the online environment was shared with the students and after the consent of the students was obtained; their participation was provided on a voluntary basis. After completing the data collection, in line with the purpose of the research, first of all, the unconditional self-acceptance and compassion levels of the participants were examined in terms of variables such as gender, age, university and grade level, academic achievement, practice and volunteer work status, family's economic status and place of residence, and parental attitudes. Then, multiple regression analysis was performed to determine whether the participants' compassion and various socio-demographic characteristics predict unconditional self-acceptance. 
In the study, it was seen that the unconditional self-acceptance level of the participants is intermediate and their compassion level is high. It was found that there is a very low but statistically significant relationship between the unconditional self-acceptance level and compassion level of the participants, and compassion explains $.03 \%$ of unconditional self-acceptance $(\mathrm{R}=.17, \mathrm{~F}(1-368)=11.027, \mathrm{p}<.01)$.

As a result of the research, it was understood that gender, parental attitudes, and frequency of applying religious beliefs significantly explain unconditional self-acceptance. However, there is no significant relationship between the unconditional self-acceptance level and variables such as age, grade level, academic achievement, practice and volunteer work in an NGO, economic status of the family and settlement.

It is important that students studying in the social work program try to get to know and accept themselves with their strengths and weaknesses before starting to work with individuals and communities in need. A prospective social worker with a low level of awareness and unconditional self-acceptance is likely to experience emotional difficulties if he/she encounters people exposed to violence, abuse and trauma in his/her professional life. In this respect, candidate social worker students should develop their skills to contribute to the well-being and functionality of the service recipients on the one hand, and to manage their own emotions effectively. As a result of this research, it was understood that more emphasis should be placed on the practices to develop skills in the courses in the social work program.

The results obtained from this research are limited to the students studying in the social work program of two state universities. It may be recommended to conduct more extensive research involving students studying at different universities and different programs. In addition, it can be said that it will be useful to examine candidate social worker students' characteristics such as empathy, stress coping and problem solving. 